\title{
Local Protocol Standard Cancer Center Information Summary
}

National Cancer Institute

\section{Source}

National Cancer Institute. Local Protocol Standard Cancer Center Information Summary.

NCI Thesaurus. Code C39445.

The Local Protocol, Standard Cancer Center Information Summary for Cancer Center Support Grant Application, is a study conducted by the reporting Cancer Center primarily in its catchment area (including institutional trials, either exclusive to the Center or in collaboration with other Centers, industry-sponsored trials, and other externally peerreviewed trials). 